\title{
Warmer, deeper, and greener mixed layers in the North Atlantic subpolar gyre over the last $\mathbf{5 0}$ years
}

\author{
Martinez Elodie 1, 2, ${ }^{*}$, Raitsos Dionysios E. ${ }^{3}$, Antoine David 4, 5, 6
}

1 UPF, IFREMER, IRD, EIO,UMR 241, Tahiti, Fr Polynesia.

2 ILM, Tahiti, Fr Polynesia.

3 Plymouth Marine Lab, Plymouth, Devon, England.

${ }^{4}$ Curtin Univ, Dept Phys Astron \& Med Radiat Sci, Remote Sensing \& Satellite Res Grp, Perth, WA 6845, Australia.

${ }^{5}$ Univ Paris 06, LOV, UMR 7093, Villefranche Sur Mer, France.

6 Univ Paris 04, CNRS, Observ Oceanol, Villefranche Sur Mer, France.

* Corresponding author : Elodie Martinez, email address : elodie.martinez@ird.fr

\begin{abstract}
:
Shifts in global climate resonate in plankton dynamics, biogeochemical cycles, and marine food webs. We studied these linkages in the North Atlantic subpolar gyre (NASG), which hosts extensive phytoplankton blooms. We show that phytoplankton abundance increased since the 1960s in parallel to a deepening of the mixed layer and a strengthening of winds and heat losses from the ocean, as driven by the low frequency of the North Atlantic Oscillation (NAO). In parallel to these bottom-up processes, the top-down control of phytoplankton by copepods decreased over the same time period in the western NASG, following sea surface temperature changes typical of the Atlantic Multi-decadal Oscillation (AMO). While previous studies have hypothesized that climate-driven warming would facilitate seasonal stratification of surface waters and long-term phytoplankton increase in subpolar regions, here we show that deeper mixed layers in the NASG can be warmer and host a higher phytoplankton biomass. These results emphasize that different modes of climate variability regulate bottom-up (NAO control) and topdown (AMO control) forcing on phytoplankton at decadal timescales. As a consequence, different relationships between phytoplankton, zooplankton, and their physical environment appear subject to the disparate temporal scale of the observations (seasonal, interannual, or decadal). The prediction of phytoplankton response to climate change should be built upon what is learnt from observations at the longest timescales.
\end{abstract}

Keywords : AMO, bottom-up processes and top-down control, chlorophyll, climate cycles, Continuous Plankton Recorder, NAO, North Atlantic subpolar gyre, phytoplankton decadal variability, plankton climate links 


\section{Introduction}

Phytoplankton (the microalgae that populate the upper lit layers of the ocean) fuel the oceanic food web and affect oceanic and atmospheric carbon dioxide levels through photosynthetic carbon fixation. The North Atlantic Subpolar Gyre (NASG) is home of the most widespread phytoplankton blooms globally, and is currently one of the largest oceanic sinks of atmospheric $\mathrm{CO}_{2}$ (Sabine et al., 2004). Observations in this area were used by Sverdrup (1953) to elucidate the conditions leading phytoplankton to bloom. Later on, the role of upper ocean stratification and dynamics (bottom-up processes) on the seasonal to interannual variability of phytoplankton in this region has been largely investigated using

This article is protected by copyright. All rights reserved. 
recent (< 15 years) satellite ocean color observations (Dutkiewicz et al., 2001; Follows \& Dutkiewicz, 2002; Siegel et al., 2002; Behrenfeld, 2010). Top-down control, i.e., zooplankton grazing, has been investigated on longer time scales using sustained biological observations mainly in the northeastern Atlantic and adjacent coastal seas (Beaugrand \& Reid, 2003). In these regions, observations revealed that phytoplankton changes over 1950-2000 were related to both top-down control and sea surface temperature variability (Edwards et al., 2002; Barton et al., 2003).

Coupled bio-physical models include the mechanisms of these controls, yet they diverge in reproducing decadal observations (Henson et al., 2009; Patara et al., 2011), in particular phytoplankton regime shifts (Henson et al., 2009b). Phytoplankton grow as a result of the combined supply of nutrients and light in the upper layers of the ocean. Vertical mixing of the water column can upwell nutrients up to the euphotic layer, resulting in a positive relationship between mixing and nutrient concentrations. In contrast, vertical mixing could also entrain phytoplankton down to depths where sunlight does not penetrate, generating light-limitation of photosynthesis and a negative relation between mixing and average available light. Both effects coexist in subpolar regions such as the NASG, where phytoplankton are light-limited in winter and subsequently bloom in spring when light increases and the mixed layer (ML) shallows. This bloom ends when phytoplankton are either starved of nutrients and/or grazed by zooplankton. On time scales from inter-annual to decadal, a decrease of winter mixing in subpolar regions due to global warming would reduce the time during which the ML is deeper than the illuminated upper layer. The consequence of such a shallower mixed layer depth would be an earlier start of the phytoplankton spring bloom and enhanced phytoplankton biomass (Doney, 2006). Contrary to this scheme, however, an increase of phytoplankton biomass has been reported in the NASG over the last decades (Reid et al., 1998; Raitsos et al., 2005; Henson et al., 2009b) although the ML has deepened (Carton et 
al., 2008) and has become warmer (Sutton \& Hodson, 2005). The comparison of historical and contemporaneous satellite ocean color observations has also revealed that phytoplankton biomass was higher and ML was deeper in the North Atlantic Ocean in the 2000s as compared to the 1980s (Martinez et al., 2011).

Therefore uncertainties on interactions among phytoplankton, zooplankton, and the physical environment at decadal scales are still large. These interactions are sensitive to climate (Behrenfeld et al., 2006; Martinez et al., 2009; Boyce et al., 2010), and need to be better understood in order to forecast the future evolution of phytoplankton. Studies of these linkages are, however, usually limited by the short duration of available observations with respect to decadal time scales.

The aim of this study is to assess relationships between phytoplankton decadal variability and bio-physical dynamics in the NASG $\left(40^{\circ}-15^{\circ} \mathrm{W} ; 50^{\circ}-60^{\circ} \mathrm{N}\right.$; blue and red boxes on Fig. 1). This study addresses three questions: 1) how are stratification and phytoplankton biomass variability related at decadal time-scales? 2) How does top-down control influence phytoplankton decadal variability? 3) To which climate modes are decadal changes in bottom-up and top-down processes related to?

\section{Materials and methods}

Plankton datasets (phytoplankton and zooplankton) are acquired from the Continuous Plankton Recorder (CPR) survey, which consistently samples the upper ocean in the North Atlantic Ocean and North Sea using a virtually unchanged methodology since 1948 (Richardson et al., 2006). The Phytoplankton Color Index (PCI), a proxy of phytoplankton biomass has been extensively used to describe major spatio-temporal patterns of phytoplankton (Reid et al., 1998; Head \& Pepin, 2010), and has been validated with in situ and remotely sensed datasets (Raitsos et al., 2013). Here, phytoplankton biomass is expressed

This article is protected by copyright. All rights reserved. 
in terms of chlorophyll concentration $\left(\mathrm{Chl}, \mathrm{mg} \cdot \mathrm{m}^{-3}\right)$, which was derived from a calibration of the PCI using satellite ocean color observations (Raitsos et al., 2005; Henson et al., 2009b). In addition to PCI, taxonomic information (i.e. diatoms and dinoflagellates abundances) is also acquired from the CPR database to investigate changes in community structures. Abundances of these phytoplankton functional groups are number of counts per sample, which represents $\sim 3 \mathrm{~m}^{3}$ of filtered seawater.

Zooplankton are key components in the marine food-web of the subarctic North Atlantic. To account part of the top-down control, the abundance of the CPR total Calanus and total copepods was acquired. These zooplankton taxonomic groups include Calanus Finmarchicus which is one of the most commonly found species of zooplankton, accounting for the majority of copepod abundance in the subarctic waters of the North Atlantic.

We have used the CPR datasets over 1960-2010 in three well-sampled regions based on Henson et al. (2009b). However, the western and eastern NASG areas have been slightly reduced in the present study (Fig. 1) as compared to Henson et al. (2009b; their Fig. 1) to ensure that the open-ocean NASG is considered separately from coastal regions: the Western part of the NASG (W-NASG; 20000 samples), the Eastern part of the NASG (E-NASG, 19500 samples) and the more coastal Northeastern Atlantic/ North Sea region (N-Seas; $\sim 61000$ samples).

Mixed-layer depth (MLD) and sea-surface temperature (SST) are issued from the Simple Ocean Data Assimilation (SODA, version 2.1.6; http://soda.tamu.edu; Carton \& Giese, 2008) over $1960-2008$ on a $0.5^{\circ}$ grid. MLD is determined as being the depth where the potential density is $0.03 \mathrm{~kg} \cdot \mathrm{m}^{-3}$ higher than its value at $10 \mathrm{~m}$ (de Boyer Montégut et al., 2004). Monthly wind speeds over 1960-2009 are issued from the Woods Hole Oceanographic Institute Objectively Analysed Air-Sea Fluxes-V3 (WHOI OAFlux) available on a $1^{\circ}$ grid (http://oaflux.whoi.edu; Yu et al., 2008). Monthly net heat losses from the ocean are issued

This article is protected by copyright. All rights reserved. 
from the National Center for Environmental Prediction / National Center for Atmospheric Research (NCEP/NCAR) 40-year reanalysis, available on a T62 Gaussian grid $\left(\sim 1.9^{\circ}\right.$ grid) over 1960-2010 (http://www.esrl.noaa.gov/psd; Kalnay et al., 1996).

The monthly NAO index since January 1950 is derived through a rotated principal component analysis of monthly standardized $500-\mathrm{mb}$ height anomalies over $20^{\circ} \mathrm{N}$ to $90^{\circ} \mathrm{N}$ and is provided by the Climate Prediction Centre (http://www.cpc.ncep.noaa.gov). The monthly, unsmoothed AMO index since 1948 is provided by the National Oceanic and Atmospheric Administration (NOAA) Earth System Research Laboratory. The time series is the area-weighted average over the North Atlantic $\left(0^{\circ} \mathrm{N}-70^{\circ} \mathrm{N}\right)$ derived from the Kaplan SST dataset (http://esrl.noaa.gov).

Biological and physical parameters have been spatially averaged over each region. Available raw monthly CPR data can be seen on Figure 2 (colored plate). Years with more than four missing months and with three consecutive missing months were removed from the analysis. Linear interpolations in time were carried out and annual means were calculated. A linear interpolation in time has been performed on the annual mean of CPR data to fill the 1year gap in 1982 in the W-NASG, and in 1996 and 2009 in the E- NASG. As the time series of the monthly physical parameters had full time-coverage, their annual means were calculated without any statistical treatment. Anomalies are computed as the difference between the average of a given year minus the mean of the entire series. By removing the seasonality from the data set and computing correlations on the residuals, temporalautocorrelation is reduced. Cumulative sum of these anomalies are derived to detect changes of a given parameter, as well as the intensity and duration of its decadal variability (Leterme et al., 2005, 2008). Successive positive residuals are observed when annual values are consistently above the climatological average, producing an increasing slope, and conversely. No slope shows a succession of values similar to the mean. Note that the cumulative sum

This article is protected by copyright. All rights reserved. 
method is sensitive to missing data, thus, due to excess data gap in the CPR dataset over 1986-1990, this method was not applicable to W-NASG.

In order to quantify the spatial and temporal decadal variability of physical parameters (i.e., MLD, wind speed, SST, net heat flux) in the NASG over the last five decades, Empirical Orthogonal Function analyses (EOFs) have been performed on annual anomaly fields (see supplemental figures).

\section{Results}

\section{Phytoplankton decadal variability in the NASG}

A sharp Chl increase over 1985-1991 delineates a regime with lower Chl concentrations before 1985 and a regime with higher concentrations after 1990 in the N-Seas (Fig. 2a). This change has been previously reported (e.g., Edwards et al., 2001; Raitsos et al., 2014). The corresponding anomaly of annual $\mathrm{Chl}\left(\mathrm{Chl}_{\mathrm{ano}}\right)$ and the corresponding cumulative sum are displayed as the black and red curves, respectively, to highlight the timing and duration of decadal changes. The descending (ascending) slope of the cumulative curve before (after) the mid-1980s corresponds to the period with below-average (above-average) $\mathrm{Chl}_{\text {ano }}$. These patterns are partly observed in the W-NASG (Fig. 2b), where Chl values are also higher after the mid-1980s in comparison to their values before that time. Chl reacts differently in the ENASG (Fig. 2c). A sharp increase occurs from the mid-1980s to the mid-1990s. Then, Chl decreases and the cumulative sum shows values close to average (i.e., no slope) vs. lower than average values (descending slope) before 1985. These Chl trends were reported till 2004 by Henson et al. (2009b) in the NASG and N-Seas, and they appear to be maintained till 2010 (Fig. 2a-c).

This article is protected by copyright. All rights reserved. 


\section{Changes in community structures}

Diatoms and dinoflagellates are phytoplankton functional types key to the classic North Atlantic spring bloom scenario. Thus, they could be used to better understand the processes leading to the decadal variability observed in Chl. In the NASG, diatoms bloom in spring, followed by dinoflagellates and other small phytoplankton in summer (McQuatters et al., 2007). The interannual variability of $\mathrm{Chl}_{\mathrm{ano}}$ in the W-NASG is well correlated with anomalies of diatom and dinoflagellate abundance ( $\mathrm{r}=0.52$ and 0.5 , respectively, $\mathrm{p}<0.01$; Fig. $3 \mathrm{a}$ ). Similar relationships hold in the E-NASG ( $r=0.62$ and $0.47, p<0.01$; Fig. $3 b$ ). The decadal trends of $\mathrm{Chl}_{\mathrm{ano}}$ in the W-NASG and E-NASG are also observed for diatom and dinoflagellate abundance. In the W-NASG, the post-1980s increase of Chl is associated with an increase of diatoms from March to September and of dinoflagellates from May to October (Fig. 3c). In the E-NASG, the sharp increase of Chl over 1986-1995 corresponds to a large increase in diatom and dinoflagellate abundance (Fig. 3b) from April to October and June to November, respectively (Fig. 3d, vertical bars with horizontal hatched).

There is a good correspondence between changes in abundance of diatoms and dinoflagellates and changes in Chl in the W- and E-NASG (except after 1996 in the E-NASG where abundance of diatoms and dinoflagellates decreases while $\mathrm{Chl}_{\text {ano }}$ is moderately above the average). Although part of the phytoplankton community that contributes to $\mathrm{Chl}$ is not captured by the CPR (e.g. picophytoplankton), this result suggests $\mathrm{Chl}$ as a good indicator of phytoplankton biomass in the sub-polar gyre, contrary to more oligotrophic areas where phytoplankton photo-adaptation may jeopardize the Chl-biomass relationship (Siegel et al., 2013).

This article is protected by copyright. All rights reserved. 
Decadal variability in stratification, and associated climate modes

We investigated the role of MLD, winds, heat loss from the ocean and SST in forcing the decadal variability of plankton. These parameters are issued from models or objectively analyzed products. Their full spatial coverage along time allows the investigation of their spatio-temporal variability over the last five decades. EOFs performed on the different physical parameters all show that: 1) The spatial variability of the first component is homogenous (i.e., of the same sign everywhere in the domain) within each region (see wind speed and SST as examples on Fig. S1a and S2a, respectively); and 2) The associated first principal component (PC) closely follows the annual means averaged over each region (Fig. S1c and S2b, black line vs. colored lines). These results imply that the spatially averaged time-series of the physical parameters (which are ultimately compared with the biological data) are representative of the variability within each area. Winds, net heat fluxes and MLD variability at decadal scales are strongly related in the NASG (see Fig. S1d,e), the two formers being two main drivers of the MLD variability. Processes involved in the N-Seas are discussed in the last section.

The decadal variability in winds, heat loss from the ocean, and MLD, follows the low frequency signal of the NAO in both E- and W-NASG (black line vs. shaded area on Fig. 4a,b; Fig. S1d,e) (Eden \& Willebrand, 2001; Visbeck et al., 2003). Changes in the slopes of the cumulative sums highlight that, before 1980, the negative phase of the NAO (NAO-) resulted in weaker westerlies and weaker heat loss from the ocean, leading to shallower MLD (downward slope). Then, the NAO turned positive (NAO+) in the early 1980s and further strengthened in the mid-1980s, associated with stronger winds, stronger heat loss from the ocean, and deeper ML (upward slope). In the mid-1990s the NAO turned from a strong to a moderate NAO+ (horizontal slope). Figures $4 \mathrm{a}$ and $\mathrm{S} 1 \mathrm{~b}$ illustrate these wind speed changes between strong and moderate NAO+ conditions, homogenous across the NASG. Our results

This article is protected by copyright. All rights reserved. 
highlight that the observed changes in physics are related to the broader climate (as seen by climate indices).

\section{Bottom-up processes}

Weaker mixing is associated with weaker (below average) phytoplankton biomass before 1980 under NAO- conditions, and vice-versa after the mid-1980s, in both E- and W-NASG (Fig. 4a,b respectively, black vs. green lines and shaded areas). Stronger winds and heat losses from the ocean in winter under NAO+ conditions lead to deeper MLs. The wintertime MLD maximum is about $25 \mathrm{~m}$ and $45 \mathrm{~m}$ (up to $150 \mathrm{~m}$ some years) deeper on average after the mid-1980s in the W- and E-NASG, respectively. This ML deepening possibly induced a larger nutrient input to the surface, creating favorable conditions for phytoplankton increase in spring and summer. Consistently, higher Chl are associated with higher abundances of diatoms and dinoflagellates in the W-NASG (E-NASG) over 1986-2010 (1986-1995) than prior to 1985 . The increase of diatoms during NAO+ events could be related with nutrient richer waters in early spring due to deeper MLs but also to their ability to grow quickly under turbulent conditions (Margalef, 1973, 1997). Then, a larger pool of recycled nutrients could be available in summer, allowing the increase of dinoflagellates and secondary production.

Deeper MLs during winter could be expected to extend the duration of the period when phytoplankton growth is light limited. Consequently, the initiation of phytoplankton blooms would be delayed, the growth season shortened, and the annual phytoplankton biomass decreased as shown in the modeling study by Henson et al. (2009). On the other hand, modeling has also shown that deeper mixing occurring during $\mathrm{NAO}+$ conditions at subpolar latitudes can cause a decrease in late winter Chl due to light limitation, which is however overcome by an increase in spring Chl due to higher nutrient availability (Patara et al., 2011). While our results do not show a shortened growth season, possibly due to the monthly resolution, they appear to be in agreement with an increase in spring $\mathrm{Chl}$ as in Patara et al.

This article is protected by copyright. All rights reserved. 
(2011) (Fig. 2b,c for Chl, Fig. 3c,d for community structures). Thus, stronger winds and deeper MLs possibly associated with a larger nutrient pool could enhance phytoplankton biomass in the NASG under NAO+ conditions.

\section{Top-down control}

We finally considered the top-down control (i.e., grazers controlling the abundance of phytoplankton) through the variability of total Calanus and total copepod abundances as well as their ratio in the NASG. Mesozooplankton are important consumers of phytoplankton, particularly in productive ecosystems (Calbet, 2001).

Year-to-year fluctuations in Calanus follow that of total copepods in the NASG (not shown). In the W-NASG, annual anomalies of Calanus and copepod abundances are anticorrelated with $\mathrm{Chl}_{\mathrm{ano}}$ over 1960-1987 $\left(\mathrm{r}_{1960-1987}=-0.46, \mathrm{p}<0.01\right)$ and after 1996 (Fig. 4c, red vs. green line). Negative correlations between abundances of predator and prey highlight the impact of top-down control in this region as postulated by Frank et al. (2005). This copepodChl anti-correlation, which occurs over almost forty years, is temporarily disrupted from 1991 to 1995 with simultaneous positive anomalies in Chl and copepod abundances. This increase of copepods is not associated with a parallel drop of Chl, suggesting a temporary decoupling between phytoplankton and copepods.

This decadal variability of Chl concentrations and copepod abundance could be related through at least two processes. First, changes in MLD may influence the disturbancerecovery cycle following concepts proposed by Behrenfeld et al. (2013). Second, changes in SST are known to influence zooplankton abundance and community structures.

The disturbance-recovery hypothesis proposes that deep winter mixing generates a spatial decoupling between phytoplankton and their predators (zooplankton). Pressure from grazers on the phytoplankton population would be relieved by decreasing their encounter rates. Springtime stratification would enhance phytoplankton specific growth rates, while This article is protected by copyright. All rights reserved. 
simultaneously intensifying loss rates by predation, effectively 'recoupling' predators and prey when they become confined to a smaller water volume. Modeling has shown that deeper mixing would consistently yield greater winter decoupling between phytoplankton divisions and grazing losses and, consequently, higher phytoplankton inventories (Behrenfeld et al., 2013).

Copepods are known to be temperature sensitive (Beaugrand et al., 2002, 2003; Beaugrand, 2012), thus we investigated their changes in parallel to changes in SST. As mentioned in the bottom-up section, the spatial variability of the SST first component is homogenous (i.e., of the same sign everywhere in the domain) within each region (Fig. S2a), and is representative of the spatially averaged annual mean variations in the NASG (Fig. S2b, black vs. colored lines). The AMO index well describes SST decadal variability in the NASG. Colder SST and a cold phase of the AMO can be observed prior to 1996 in the NASG (shaded area on Fig. S2b and Fig. 4c). Then, a shift to a warm phase occurs. In the mid-1990s when warmer SST associated with the AMO warm phase takes place, zooplankton abundance decreases $\left(\mathrm{r}_{\text {sst-ttcop }}=-0.43, \mathrm{p}<0.01 ; 43\right.$ cells per sample on average over 1960-1987 vs. 30 over 1996-2010; Fig 4c) as well as the abundance of total Calanus compared to total copepods decreases by up to $20 \%\left(\mathrm{r}_{\text {sst-cal } / \text { cop }}=-0.52, \mathrm{p}<0.01 ;\right.$ Fig. $\left.4 \mathrm{~d}\right)$.

Thus, before the mid-1980s, the NAO- regime provides unfavorable bottom-up and topdown conditions with low MLD leading to a low nutrient pool and possibly a weak decoupling between phytoplankton and grazers, reducing phytoplankton biomass. In addition, before the mid-1990s, the AMO- regime also provides unfavorable top-down conditions with cold SST leading to high copepod abundance also reducing phytoplankton biomass. Conversely, after the mid-1980s, the NAO+ regime provides more favorable bottom-up and top-down conditions with deeper MLD leading to a higher nutrient pool and a greater decoupling between phytoplankton and grazers, enhancing phytoplankton biomass. In

This article is protected by copyright. All rights reserved. 
addition, after the mid-1990s, the AMO+ regime also provides favorable top-down conditions with warmer SST leading to lower copepod abundance also enhancing phytoplankton biomass. From 1996 onwards, the abundance of total Calanus also decreases by up to $20 \%$ as compared to total copepods (Fig. 4d, blue line). Such a change in the zooplankton community structure possibly also modifies the grazing pressure on phytoplankton. Finally, the 19911996 temporary parallel increase of both phytoplankton and copepods occurs when the NAO and AMO low frequency regimes are out of phase (NAO+ vs. AMO-). Under AMO-, zooplankton abundance remains high and changes in community structures have not yet occurred. The expected prey-predator decoupling under NAO+ seems to be overcame by the bottom-up control. During this time period when wind, MLD and net heat flux undergone their strongest increase over the five decades, the associated strong input of nutrients would be the main driver of the strong $\mathrm{Chl}$ increase followed by a strong zooplankton increase.

In the E-NASG, Calanus and copepod mean abundance and standard deviation are lower than in the W-NASG $(6.3 \pm 4.4$ vs. $41.2 \pm 23.7$ cells per sample, respectively $)$. This weaker grazing pressure possibly explains the weak correlation between copepods and phytoplankton (Fig. S3), and a weaker top-down control contributing to higher phytoplankton abundance than in the western region. Moreover, according to the decoupling-recovery theory, and as shown in Behrenfeld et al. (2013), the top-down control would be less efficient in this deep wintertime mixed layer maximum environment. In the E-NASG, the wintertime maximum MLD is on average 60 to $85 \mathrm{~m}$ deeper (before and after 1985, respectively) than in the WNASG, possibly inducing a lower top-down control.

This article is protected by copyright. All rights reserved. 


\section{DISCUSSION:}

Decadal changes in phytoplankton abundance in the whole NASG have been shown here to be associated with the changes of bottom-up, and possibly top-down forcing, related to the low frequency regimes of the NAO. Our results show that phytoplankton has increased as the mixed layer became deeper. The expected paradigm would be that this increase of phytoplankton is observed when the ML becomes shallower due to surface warming in the subpolar region (Doney, 2006). We hypothesize that under NAO+ conditions, the observed stronger winds, stronger heat losses from the ocean, and increased mixing, have enhanced nitrate availability in the euphotic zone (Patara et al., 2011; Henson et al., 2012), thus possibly explaining the higher $\mathrm{Chl}$ concentrations and higher diatom/dinoflagellate abundances observed after 1985. The decrease of the prey-predator encounter rate that can be expected when the mixed layer is deeper (Behrenfled et al., 2013) is another possible cause of the increased phytoplankton abundance. The possible influence of the AMO on top-down control of phytoplankton by copepods has been shown for the western region. In this area a lower grazing pressure due to higher SST under AMO+ conditions would also have provided better conditions for phytoplankton growth.

It is expected that warming in subpolar regions would lead to shallower MLs and an increase of phytoplankton due to less light limitation (Doney, 2006). Consistently with the first part of this paradigm concerning SST and MLD, we found shallower MLs associated with warmer SST during NAO- conditions in the 1960s-1980s, compared with deeper MLs and colder SST during strong NAO+ conditions over the mid 1980s-1990s. Then, this covariability breaks down after 1995 when the AMO turns into a warm phase while the NAO remains positive. Thus, ML remains deeper than before the 1980s while SST becomes warmer partly contradicting the paradigm. A switch over, from a cold subpolar gyre during a positive NAO index phase to a warmer than normal state, seems to occur if the positive phase

This article is protected by copyright. All rights reserved. 
persists for more than 6-8 years (Visbeck et al., 2003). These changes in temperature are caused by the advection of warmer water from the subtropical gyre region, driven by a spinup of the Atlantic meridional overturning circulation and the effect of an anomalous wind stress curl in the north-eastern Atlantic, which counteracts the local buoyancy forcing of the subpolar gyre (Lohmann et al., 2009). Finally, the deeper ML associated with warmer SST after 1995 shows that MLD and SST are not interchangeable indicators of the stratification level of the upper ocean in this region over the last decades. This is in accordance with recent observations in the North Atlantic subtropical gyre (Lozier et al., 2011), as well as in the transition zone near the subpolar gyre between the 1980s and 2000s (Martinez et al., 2011).

The phytoplankton step-wise increase in the mid-1980s has been widely reported in the $\mathrm{N}$-Seas in parallel to changes in zooplankton community structures following the Northern Hemisphere Temperature warming since the 1980s (Beaugrand et al., 2002; Beaugrand, 2012). Interestingly, this warming occurs almost 10 years earlier in the N-Seas than in the Wand E-NASG (Fig. S4b purple line vs. Fig. S2b blue and red lines, respectively). The first PC derived from the SST EOFs represents most of the SST annual signal in the N-Seas (Fig. S4b black vs. purple line, respectively) as well as the post-1996 warming related with the AMO index. However, the 1988-1995 earlier warming in the N-Seas than in the NASG can be related with $\mathrm{NAO}+$ conditions as shown on the second PC $(9.5 \%$ of the total variance, Fig. S4c purple vs. black line and shaded area). The associated second spatial component illustrates how the NAO can simultaneously increase ocean temperatures in one part of the Atlantic basin, while reducing them in another (Fig. S4a). Although the NASG region is cooler during NAO+ conditions, the N-Seas becomes warmer (Rodwell, 1999; Leterme et al., 2005). Thus, the decrease of total copepods and Calanus in the N-Seas follows a warming since the end of the 1980s (Fig. 4e) likely due to both NAO+ and AMO+ conditions. The increase of phytoplankton biomass is likely related to both a weaker top down control and

This article is protected by copyright. All rights reserved. 
favorable bottom-up conditions (i.e., higher nutrients) partly associated with stronger winds and net heat loss from the ocean over the last 2.5 decades (Fig. $4 \mathrm{e}$ ).

Our results illustrate how the different biomes of the North Atlantic (Longhurst, 2007) may react differently to climatic variations, although the intermingled bottom-up and topdown controls cannot be fully separated here. They reveal the complex effects of climate oscillations on bottom-up and top-down controls of phytoplankton variability. These results also emphasize the critical importance of historical datasets in our search for long-term (decadal) changes, trends and regime shifts that modify bottom-up and top-down forcings.

\section{Acknowledgements}

We are grateful to past and present staff of SAHFOS who have contributed to the maintenance of the CPR time series. Particular thanks to David Johns for his advice on CPR datasets and methods. The authors gratefully acknowledge the data sources for this study: the WHOI OAFlux project funded by the NOAA Climate Observations and Monitoring (COM) program, the NCEP Reanalysis Derived data provided by the NOAA/OAR/ESRL PSD, Boulder, Colorado, USA. This work was supported by a grant from the Changing Earth Science Network initiative funded by the STSE program of the European Space Agency (ESA). We thank H. Claustre, G. Beaugrand, and R.J. Brewin for the comments they provided on early versions of the manuscript. We also thank the two anonymous reviewers and the editor for their insightful comments which helped improve the manuscript.

\section{References}

Barton AD, Greene CH, Monger BC, Pershing AJ (2003) The Continuous Plankton Recorder survey and the North Atlantic Oscillation: Interannual- to multidecadal-scale patterns of phytoplankton variability in the North Atlantic Ocean. Progress in Oceanography, 58, 337- 358.

Beaugrand G, Reid PC, Ibanez F, Lindley JA, Edwards M (2002) Reorganization of North Atlantic marine copepod biodiversity and climate. Science, 296, 1692-1694.

Beaugrand G, Reid PC (2003) Long-term changes in phytoplankton, zooplankton and salmon related to climate. Global Change Biology, 9, 801-817.

Beaugrand G (2012) Unanticipated biological changes and global warming. Marine Ecology-Progress Series, 445, 293-301.

Behrenfeld MJ, O'Malley RT, Siegel DA et al. (2006) Climate-driven trends in contemporary ocean productivity. Nature, 444, 752-755.

Behrenfeld MJ (2010) Abandoning Sverdrup's Critical Depth Hypothesis on phytoplankton blooms. Ecology, 91, 977-89.

Behrenfeld MJ, Doney SC, Lima I, Boss ES, Siegel DA (2013) Annual cycles of ecological disturbance and recovery underlying the subarctic Atlantic spring plankton bloom. Global biogeochemical cycles, 27(2), 526-540.

Boyce DG, Lewis MR, Worm B (2010) Global phytoplankton decline over the past century. Nature, 466, 591596.

This article is protected by copyright. All rights reserved. 
Calbet A (2001) Mesozooplankton grazing effect on primary production: a global comparative analysis in marine ecosystems. Limnology and Oceanography, 46(7), 1824-1830.

Carton JA, Giese BS (2008) A reanalysis of ocean climate using Simple Ocean Data Assimilation (SODA). Monthly Weather Review, 136, 2999-301.

Carton JA, Grodsky SA, Liu H (2008) Variability of the oceanic mixed layer, 1960-2004. Journal of Climate, 1029-1047.

de Boyer Montégut C, Madec G, Fischer AS, Lazar A, Iudicone D (2004) Mixed layer depth over the global ocean: An examination of profile data and a profile-based climatology. Journal of Geophysical Research, 109, 1978-2012.

Doney SC (2006) Plankton in a warmer world. Nature, 444, 695-696.

Dutkiewicz S, Follows M, Marshall J, Gregg WW (2001) Interannual variability of phytoplankton abundances in the North Atlantic. Deep-Sea Research II, 48, 2323-2344.

Eden C, Willebrand J (2001) Mechanism of interannual to decadal variability of the North Atlantic Oscillation. Journal of Climate, 14, 2266-2280.

Edwards M, Reid P, Planque B (2001) Long-term and regional variability of phytoplankton biomass in the Northeast Atlantic (1960-1995). ICES Journal of Marine Science: Journal du Conseil, 58, 39-49.

Edwards M, Beaugrand G, Reid PC, Rowden AA, Jones MB (2002) Ocean climate anomalies and the ecology of the North Sea. Marine Ecology-Progress Series, 239, 1-10.

Follows M, Dutkiewicz S (2002) Meteorological modulation of the North Atlantic spring bloom. Deep-Sea Research II, 49, 321-344.

Frank KT, Petrie B, Choi JS, Leggett, WC (2005) Trophic cascades in a formerly cod-dominated ecosystem. Science, 308, 1621-1623.

Head EJ, Pepin P (2010) Spatial and inter-decadal variability in plankton abundance and composition in the Northwest Atlantic (1958-2006). Journal of Plankton Research, fbq090.

Henson SA, Dunne JP, Sarmiento JL (2009) Decadal variability in North Atlantic phytoplankton blooms. Journal of Geophysical Research, 114, C04013.

Henson SA, Raitsos D, Dunne JP, McQuatters-Gollop A (2009b) Decadal variability in biogeochemical models : Comparison with a 50-year ocean colour dataset. Geophysical Research Letters, 36, L21061.

Henson SA, Sanders R, Madsen E (2012) Global patterns in efficiency of particulate organic carbon export and transfer to the deep ocean. Global Biogeochemical Cycles, 26.

Kalnay E, Kanamitsu M, Kistler R et al.,(1996) The NCEP/NCAR 40-year reanalysis project. Bulletin of American Meteorological Society 77, 437-470.

Leterme SC, Edwards M, Seuront L, Attrill MJ, Reid PC, John AWG (2005) Decadal basin-scale changes in diatoms, dinoflagellates, and phytoplankton color across the North Atlantic. Limnology and Oceanography, 50, 1244-1253.

Leterme SC, Pingree RD, Skogen MD, Seuront L, Reid PC, Attrill MJ (2008) Decadal fluctuations in North Atlantic water inflow in the North Sea between 1958-2003: impacts on temperature and phytoplankton populations. Oceanologia, 50, 59-72.

Lohmann K, Drange H, Bentsen M (2009) Response of the North Atlantic subpolar gyre to persistent North Atlantic oscillation like forcing. Climate dynamics, 32, 273-285.

Longhurst A (2007) Ecological Geography of the Sea, 2nd edn. London, UK: Academic Press.

Lozier MS, Dave AC, Palter JB, Gerber LM, Barber RT (2011) On the relationship between stratification and primary productivity in the North Atlantic. Geophysical Research Letters, 38, L18609.

Margalef R (1973) Assessment of the effects on plankton, p. 301-306. In E. A. Pearson and E. De Fraja Frangipane [eds.], Marine pollution and marine waste disposal proceedings of the 2nd International Congress, San Remo, 17-21 December 1973.

Margalef R (1997) Turbulence and marine life. Scientia marina, 61, 109-123.

Martinez E, Antoine D, D'Ortenzio F, Gentili B (2009) Climate-driven basin-scale decadal oscillations of oceanic phytoplankton. Science, 326, 1253-1256.

Martinez E, Antoine D, D’Ortenzio F, de Boyer Montégut C (2011) Phytoplankton spring and fall blooms in the North Atlantic in the 1980s and 2000s. Journal of Geophysical Research, 116, C11029.

McQuatters-Gollop A, Raitsos DE, Edwards M, Attrill MJ (2007) Spatial patterns of diatom and dinoflagellate seasonal cycles in the NE Atlantic Ocean. Marine Ecology-Progress Series, 339, 301.

Patara L, Visbeck M, Masina S, Krahmann G, Vichi M (2011) Marine biogeochemical responses to the North Atlantic Oscillation in a coupled climate model. Journal of Geophysical Research, 116, C07023.

Raitsos DE, Reid PC, Lavender SJ, Edwards M, Richardson AJ (2005) Extending the SeaWiFS chlorophyll data set back 50 years in the northeast Atlantic. Geophysical Research Letters, 32, 1-4.

Raitsos DE, Walne A, Lavender SJ, Licandro P, Reid PC, Edwards M (2013) A 60 year ocean colour dataset from the Continuous Plankton Recorder. Journal of Plankton Research, 35, 158 - 164.

This article is protected by copyright. All rights reserved. 
Raitsos DE, Pradhan Y, Lavender SJ, Hoteit I, McQuatters-Gollop A, Reid PC, Richardson AJ (2014) From silk to satellite: half a century of ocean colour anomalies in the Northeast Atlantic. Global Change Biology, 20, 2117-2123.

Reid PC, Edwards M, Hunt HG, Warner AJ (1998) Phytoplankton change in the North Atlantic. Nature, 391, 546.

Richardson AJ, Walne AW, John AWG et al. (2006) Using continuous plankton recorder data. Progress in Oceanography, 68, 27-74.

Rodwell MJ, Rowell DP, Folland CK (1999) Oceanic forcing of the wintertime North Atlantic Oscillation and European climate. Nature, 398, 320-323.

Sabine CL, Feely RA, Gruber N et al. (2004) The oceanic sink for anthropogenic CO2. Science, 305, 367-371.

Siegel DA, Doney SC, Yoder JA (2002) The North Atlantic spring bloom and Sverdrup's critical depth hypothesis. Science, 296, 730-733.

Siegel DA, Behrenfeld MJ, Maritorena S et al. (2013) Regional to global assessments of phytoplankton dynamics from the SeaWiFS mission. Remote Sensing of Environment, 135, 77-91.

Sutton RT, Hodson DLR (2005) Atlantic Ocean forcing of North American and European summer climate. Science, 309, 115-118.

Sverdrup HU (1953) On conditions for the vernal blooming of phytoplankton. Journal du Conseil International pour l'Exploration de la Mer 18, 287-295.

Visbeck M, Chassignet EP, Curry RG, Delworth TL, Dickson RR, Krahmann G (2003) The ocean's response to North Atlantic Oscillation variability. The North Atlantic Oscillation: climatic significance and environmental impact, 113-145.

Yu L, Jin X, Weller RA (2008) Multidecade Global Flux Datasets from the Objectively Analyzed Air-sea Fluxes (OAFlux) Project: Latent and sensible heat fluxes, ocean evaporation, and related surface meteorological variables. Woods Hole Oceanographic Institution, OAFlux Project Technical Report. OA2008-01, 64pp. Woods Hole. Massachusetts.

\section{Supporting Information Legends}

Fig. S1: (a) Spatial patterns of the EOF first mode of the annual wind speed (25\% of the total variance) and (c) its associated principal component (black line). Anomalies of annual wind speed averaged over the W- and E-NASG and the N-Seas are reported as blue, red and purple curves respectively. The NAO index is reported as the grey shaded area. (b) Wind speed changes between strong (1986-1995) and moderate (1996-2010) NAO+ conditions as the difference of their respective means. (d) Cumulative sums of anomalies of annual wind speed (continuous curve), net heat flux (dashed curve) and MLD (dotted curve) in the E-NASG. The cumulative sum of the NAO index is reported as the grey shaded area. (e) as in (d), but in the W-NASG.

Fig. S2: (a) Spatial patterns of the EOF first mode of the annual SST (21\% of the total variance) and (b) its associated principal component (black line). Anomalies of annual SST averaged over the W- and E-NASG are reported as blue and red curves, respectively. The AMO index is reported as the grey shaded area.

Fig. S3: Anomalies of annual Chl (green curve) and total copepod abundance (red curve) in the E-NASG. The AMO index is reported as the grey shaded area.

Fig. S4: (a) Spatial patterns of the EOF second mode of the annual SST (9,5\% of the total variance) for the N-Seas region. (b) The first EOF principal component presented in Fig. S2 (black line) is reported here with the anomaly of annual SST averaged over the N-Seas

This article is protected by copyright. All rights reserved. 
(purple line). The AMO index is reported as the grey shaded area. (c) Principal component of the second EOF (black line) associated with (a). Anomaly of annual SST in the N-Seas is reported as the purple line as in (b). The NAO index is reported as the grey shaded area.

\section{Figure Legends}

Fig. 1: Spatial distribution of the CPR data over 1960-2010 in the W- and E-NASG (blue and red boxes, respectively) and the N-Seas (purple box) regions.

Fig. 2: Monthly Chl for (a) the N-Seas, (b) the W-NASG and (c) the E-NASG regions over 1960-2010, and prior to linear interpolation. Months are reported on the left axis and years on the bottom axis. Interpolated anomalies of $\mathrm{Chl}$ annual means $\left(\mathrm{mg} \cdot \mathrm{m}^{-3}\right)$ are reported on the right axis (black curves). The cumulative sums are reported as the red curve (red right axis), except in the W-NASG region due to 5-years missing.

Fig. 3: (a) and (b) Anomalies of annual Chl (green line; left axis), of diatom abundances (orange dashed line; right axis) and of dinoflagellate abundances (blue dashed-dotted line; right axis) for the W-NASG and E-NASG regions. (c) Monthly abundances of diatoms (orange vertical bars) and dinoflagellates (blue vertical bars) averaged over [1960-1986] and [1991-2010] in the W-NASG. (d) as in (c) but for the E-NASG over [1960-1985], [19861995] and [1996-2010].

Fig. 4: (a) Cumulative sums of anomalies of annual Chl (green curve) and wind speed (black curve) in the E-NASG. The cumulative sum of the NAO index is reported as the grey shaded area in (a) and (b). (b) as in (a), but in the W-NASG. Anomalies of annual Chl are shown instead of cumulative sum due to 5-years missing. (c) Anomalies of annual Chl (green curve) and total copepod abundance (red curve) in the W-NASG. The cumulative sum of the AMO index is reported as the grey shaded area in (c) and (d). (d) Percentage contribution of total Calanus in total copepods in the W-NASG (blue curve). The scale on the right axis is inverted. (e) Cumulative sums of anomalies of annual Chl (green curve), total copepod abundance (red curve), SST (grey shaded area) and wind speed (black curve) for the N-Seas.

This article is protected by copyright. All rights reserved. 


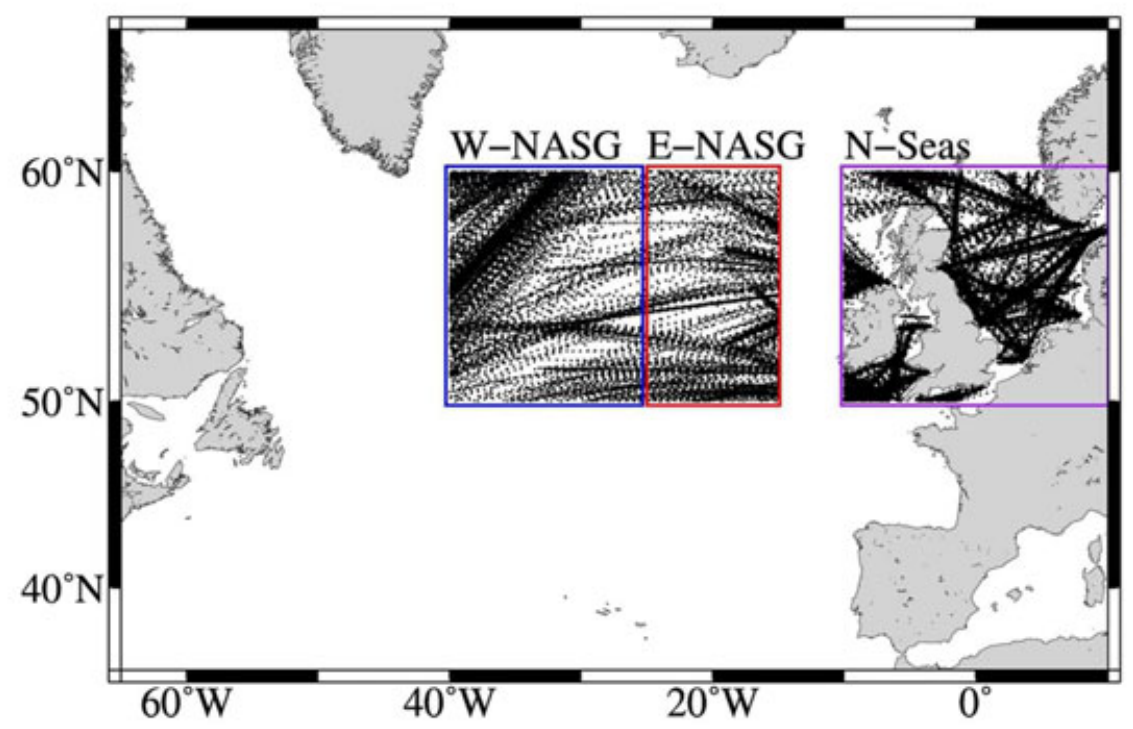

Fig. 1: Spatial distribution of the CPR data over 1960-2010 in the W- and E-NASG (blue and red boxes, respectively) and the $\mathrm{N}$-Seas (purple box) regions, $85 \times 54 \mathrm{~mm}(300 \times 300 \mathrm{DPI})$

This article is protected by copyright. All rights reserved. 


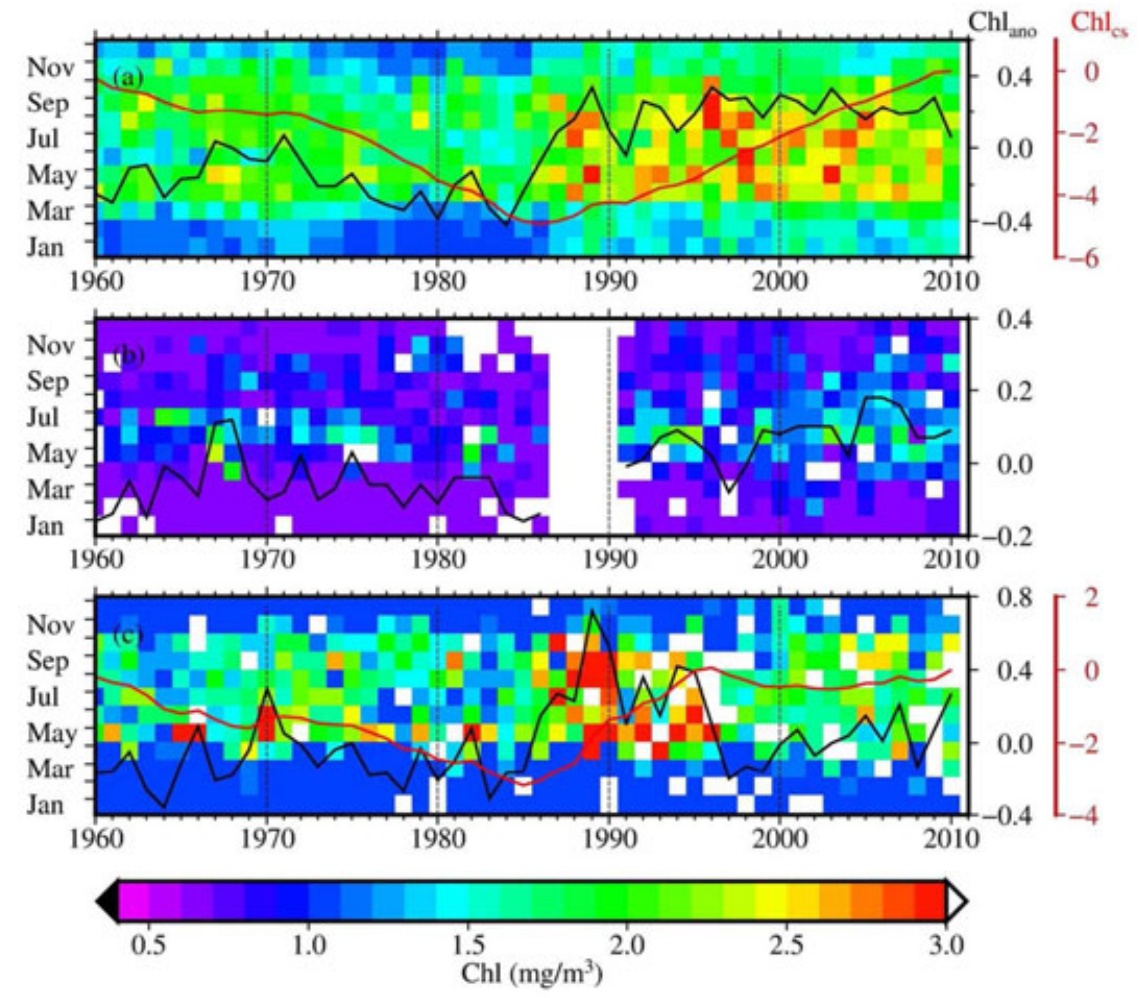

Fig. 2: Monthly Chl for (a) the N-Seas, (b) the W-NASG and (c) the E-NASG regions over 1960-2010, and prior to linear interpolation. Months are reported on the left axis and years on the bottom axis. Interpolated anomalies of $\mathrm{Chl}$ annual means (mg.m-3) are reported on the right axis (black curves). The cumulative sums are reported as the red curve (red right axis), except in the W-NASG region due to 5-years missing. $112 \times 100 \mathrm{~mm}(300 \times 300 \mathrm{DPI})$
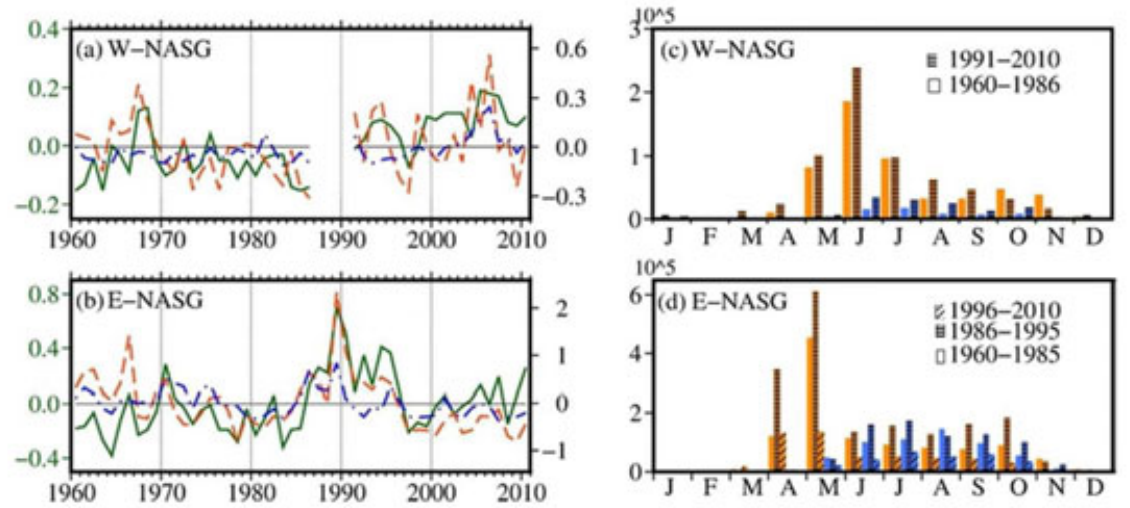

Fig 3: (a) and (b) Anomalies of annual Chl (green line; left axis), of diatom abundances (orange dashed line; right axis) and of dinoflagellate abundances (blue dashed-dotted line; right axis) for the W-NASG and ENASG regions. (c) Monthly abundances of diatoms (orange vertical bars) and dinoflagellates (blue vertical bars) averaged over [1960-1986] and [1991-2010] in the W-NASG. (d) as in (c) but for the E-NASG over [1960-1985], [1986-1995] and [1996-2010].

$64 \times 28 \mathrm{~mm}(300 \times 300 \mathrm{DPI})$

This article is protected by copyright. All rights reserved. 

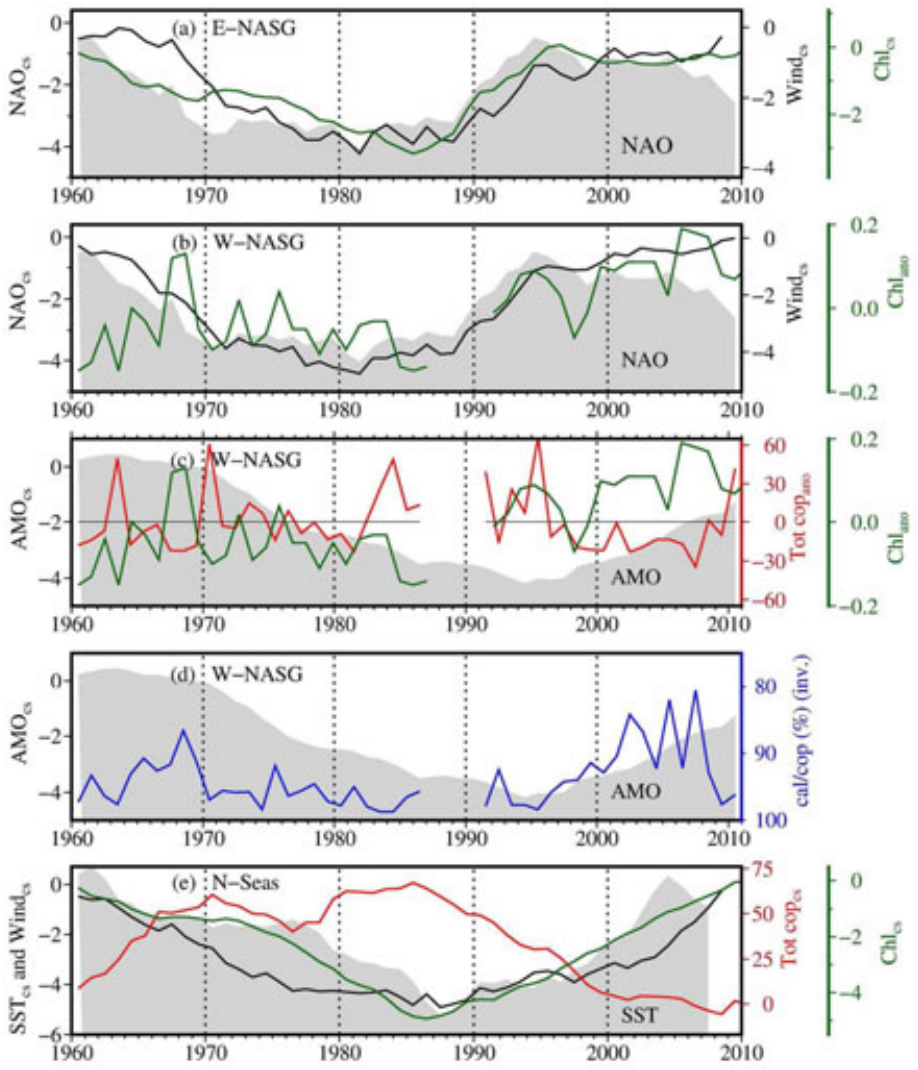

Fig 4: (a) Cumulative sums of anomalies of annual Chl (green curve) and wind speed (black curve) in the ENASG. The cumulative sum of the NAO index is reported as the grey shaded area in (a) and (b). (b) as in (a), but in the W-NASG. Anomalies of annual Chl are shown instead of cumulative sum due to 5-years missing. (c) Anomalies of annual Chl (green curve) and total copepod abundance (red curve) in the WNASG. The cumulative sum of the AMO index is reported as the grey shaded area in (c) and (d). (d)
percentage contribution of total Calanus in total copepods in the W-NASG (blue curve). The scale on the right axis is inverted. (e) Cumulative sums of anomalies of annual Chl (green curve), total copepod abundance (red curve), SST (grey shaded area) and wind speed (black curve) for the N-Seas. $157 \times 183 \mathrm{~mm}(300 \times 300 \mathrm{DPI})$

This article is protected by copyright. All rights reserved. 